$$
\begin{gathered}
\text { S sciendo International Conference KNOWLEDGE-BASED ORGANIZATION } \\
\text { Vol. XXVI }
\end{gathered}
$$

\title{
GLOBAL UNCERTAINTY DURING COVID 19 PANDEMIC AND ITS EFFECTS ON EU MEMBER STATES WITH A FOCUS ON BULGARIA
}

\author{
Mariya PASKALEVA \\ “Neofit Rilski” South-West University, Blagoevgrad, Bulgaria \\ m.gergova@abv.bg
}

\begin{abstract}
The COVID pandemic has accelerated its influence over the whole world. This corresponds to increasing policy and trade uncertainty. The uncertainty on future trade relationships impacts investors' behavior, their risk appetite, and the decline in global growth. In this paper, we aim to provide evidence on the relationship between global uncertainty and economic activity in the EU during the COVID pandemic. The applied methodology is a VAR model and a moving correlation. We discuss COVID 19 as a supply-demand shock that leads to a reduction of the productive capacity of the Bulgarian economy. The uncertainty of this pandemic causes shrinks of the demand in the private sector and an increase in the households' savings and reduction in their expenditures.
\end{abstract}

\section{Keywords: Risk, Uncertainty, Economic Activity, Financial Markets}

\section{Introduction}

The spread of COVID-19 Pandemic has upset the worldwide economy. The spread of the disease and its financial effect on the European nations is profoundly unsure. This study aims to estimate the impact of COVID-19 pandemic on the Bulgarian GDP growth and to reveal the relation between the increasing uncertainty and the European financial markets.

\section{Literature Review}

The correlation between uncertainty and economic activity is explored by many authors as in [1]. In the study, the relation between COVID-19 pandemic and uncertainty is explored. It is proved that three indicators for uncertainty may be considered as measures: stock market volatility, newspaper-based economic uncertainty, and the one in the expectations of the business. The authors use the abovementioned indicators to quantify the increasing uncertainty during the COVID-
19 pandemic and to measure the economic impact of the disease. They reveal a yearto-year contraction in U.S. real GDP growth of almost $11 \%$ as of 2020 , Q4, with a $90 \%$ confidence interval extending to almost 20\% contraction.

Paper [2] explores the economic response to the coronavirus in Europe. It is concluded that: ample national funds need to be provided to national health services; to target measures to support individuals, companies, and self-employed individuals; macroeconomic insurances need to be provided. The study recommends the EU member states to halve companies' social security contributions for three months or cut the payroll tax. The European Central Bank should prevent distress in sovereign bond markets.

Paper [3] explores the macroeconomic spillover effects of the COVID-19 pandemic on the global economy. It is proved a reduction of the GDP due to confinement measures. Spillovers across 
the countries are revealed during the current pandemic. The authors apply a model to follow out the resulting development of monetary action, mirroring the authentic connections between financial factors including the overflows and spillbacks between areas of the world. Since the immediate impact of measures is questionable, they report recreations for four elective situations. These four join two suspicions on the underlying decrease of Gross domestic product and its shape. Sizewise, the "less severe" situation is one where the immediate impact of repression estimates brings down Gross domestic product by $2.5 \%$. The "more extreme" situation pairs the impact of the repression gauges so the underlying direct hit to Gross domestic product is $5 \% .3$ This range is comprehensively steady with outer assessments of the impacts of these measures for imprisonments that the last one to two months, regardless of whether there is a huge vulnerability about the estimates.

Paper [4] estimates the European economic forecast after the COVID-19 pandemic. The pandemic struck the European economy when it was moderately and still powerless against new stuns. It has additionally snuffed out early expectations that a trough may have been arrived at when fabricating movement and remote exchange gave indications of bottoming out toward the beginning of this current year. It explains that real-time data suggest that economic activity in Europe has dropped at unusually fast speed over the last few weeks, as the containment measures triggered in response to the pandemic by most Member States in mid-March situated the economy into a state of stagnation. Economic output is estimated to collapse in the first half of 2020 with most of the reduction taking place in the second quarter.

The authors of [5] explore the influence of COVID-19 on the Slovenian economy. To assess the effect of the COVID-19 pestilence on the Slovenian economy, three situations have been structured. They fluctuate with the quantity of lock-down weeks (running from 6 to 14 weeks) and speed of recuperation following the lockdown lift. They demonstrate that the Slovenian Gross domestic product development attempts by household foundations in the period $18-23$ Walk 2020 , territories from $-2.4 \%$ to $-6.3 \%$ in the gentle (base) situations and from - 7.8\% to - $14.0 \%$ in the extreme (severe) situations.

In [6] the global macroeconomic impacts of COVID-19 are estimated. It investigates seven distinctive scenarios of how COVID19 can advance within the coming year employing a modeling strategy created by Lee and McKibbin (2003) and amplified by McKibbin and Sidorenko (2006). The paper investigates the impacts of diverse scenarios on macroeconomic results and money related markets in a worldwide half breed DSGE/CGE common balance show. The scenarios illustrate that indeed a contained outbreak may altogether affect the worldwide economy within the short run. These scenarios illustrate the scale of costs that could be maintained a strategic distance from by more noteworthy speculation in open wellbeing frameworks in all economies but especially in less created economies where wellbeing care frameworks are less created and populace thickness is high.

\section{COVID 19 pandemic and its effects on the Bulgarian economy}

Bulgaria confirmed the first case of COVID-19 on 08 March 2020. On 12 May 2020, it exists 2004 confirmed cases of coronavirus in 28 districts of the nation. There have been 93 death cases and 476 cured. On March 13,2020, the Government declared a state of emergency throughout the country for a period of one month which on April 03, 2020, was extended to May 13, 2020. After the first confirmed case, the Bulgarian government enacted different measures to "flatten the epidemic 
curve”. A list of the enacted measures is exposed below:

1. A national crisis headquarters was set up on 25 February 2020. When the first case of COVID-19 infection in Bulgaria was confirmed, schools were already closed until March 11 because of the widespread of influenza B.

2. Following the announcement of confirmed cases of coronavirus, the Bulgarian government quickly prohibited the send out of defensive gear and set orders for covers and defensive suits of neighborhood producers.

3. On March 13 in Bulgaria, after 16 confirmed cases in one day, the National Assembly voted unanimously and declared a state of emergency for the entire country by April 13, which was later extended to May 13. Schools, malls, bars, discos, shopping malls, cinemas, restaurants, gyms are closed. Also, all arrivals from Italy, Spain, Iran, South Korea, and China were placed under an obligatory 14-day quarantine. On April 16, flights from the UK were suspended.

4. On March 20, most public places are closed. Only grocery stores, pharmacies, petrol stations, banks remain open. It is forbidden to leave the regional centers in the country without a valid reason related to work, health reasons, or registration at a permanent or current address.

5. From April 12 to May 13, 2020, by order of the Minister of Health, the mandatory wearing of a face mask or other means covering the nose and mouth (towel, scarf, etc.) was introduced in public places. On May 1, the measure was eased, and wearing a protective mask outdoors is not mandatory, subject to social distance. On May 14 the national emergency was lifted, and in its place was declared a state of an emergency epidemic situation. Organ transplantations are allowed again after 2 months ban. Parks are open for use of all. Most of the anti-epidemic measures are still valid. The 14 days quarantine for everyone who enters the country remains. The schools and daycares remain closed, as well as shopping centers and indoor restaurants.

\subsection{Forecast of the dynamic of the Bulgarian GDP by VAR model}

All these aforementioned measures aim to protect the health system and Bulgarian nation but they cause a negative impact on the economy at large. When calculating the economic effects, we should consider that the COVID-19 crisis is determined as a supply-demand crisis. To measure the supply effects, arise from a loss in hours worked and raising unemployment because of the restrictive measures. The demand effects due to the psychological effects of the precautionary measures.

We apply the VAR model to forecast the Bulgarian GDP in 2020. Before proceeding with these lection of the econometric method, it is necessary to apply a stationarity test. First, it is important to estimate the stationarity of the series, because it determines its conduct. VAR model estimates the contemporaneous relationship between the variables. The VAR modelis developed to explored laggedlinks between exogenous and endogenous variables. The applied VAR model is estimated bu the following equation:

$y_{t}=A_{1} y_{t-1}+\ldots+A_{p} y_{t-p}+B x_{t}+\varepsilon_{t}$

where $y_{t}$ is a $k$ vector of endogenous variables, $x_{t}$ is avector of exogenous variables, $A_{1}, \ldots, A_{p}$ and $B$ are matrices of coefficients to be estimated and $\varepsilon_{t}$ is a vector of innovations.

The vector autoregression (VAR) is commonly used as a forecasting tool between time-related series. It estimates the contemporaneous relationship between the variables, but VAR methodology is a procedure that gives useful insights for lagged links. We apply the following variables as endogenous $\left(Y_{t}\right)$ : GDP growth rates of Bulgaria, the Bulgarian HICP, unemployment rates, and Economic Sentiment Indicators of Bulgaria. As 
exogenous variables $\left(X_{t}\right)$ : we use the following ones: GDP growth rates of the $\mathrm{EU}$, the productivity index of Bulgaria and the World Uncertainty Index. All of the explored variables are transformed into growth rates yearly to obtain stationarity. We follow paper [5] and explore a scenario with the duration of the COVID-19 pandemic from March to the middle of June (approx. 12 weeks). It is considered as a severe scenario with persistent losses.

The results from the applied VAR model are presented in Figure 1. We observe a significant influence of the COVID-19 pandemic on GDP growth in Bulgaria. The dynamic of the Bulgarian GDP for the period 2000-2020 shows that the growth rate for 2020 is equal to $-7.6 \%$ in case of a scenario, that assumes a 12-week crisis scenario. According to the results, Bulgarian GDP is forecast to contract more negative than during the Global Financial Crisis in 2009. These results confirm the forecast of the European Commission [4]. The power of the results depends on the duration of the crisis period in the EU countries.The contraction of the Bulgarian GDP is deeper than the contraction during the financial crisis in 2008. This may be explained by high levels of global uncertainty, lower level of production, lower employment, and a reduction in foreign investment. The tourism industry will be affected most severely due to restrictive measures.This suggests that the recovery period will be gradual, namely the curve will be U-shaped, rather than a rapid $\mathrm{V}$-shaped form.

GDP

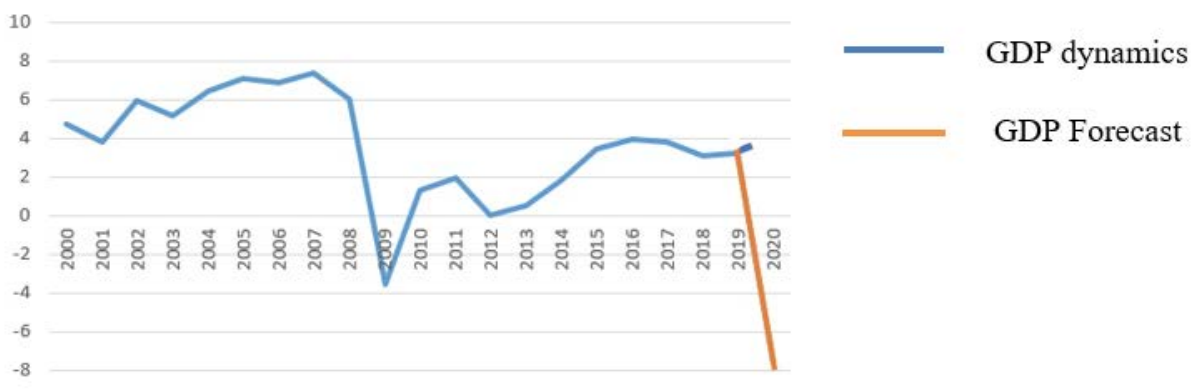

Figure 1: Dynamic and Forecast of Gross GDP Growth of Bulgaria

\section{European financial markets and Economic Uncertainty}

To estimate the uncertainty and its effects on market participants in the European markets, we apply moving correlation to reveal the potential changes in the comovements between VSTOXX Index and European Economic Policy Uncertainty Index (EPU). EPU reflects the longer-term expectations of market participants. VSTOXX Index is considered as a benchmark index for European financial markets. It represents the implied volatility of options incorporated inthe EuroStoxx 50 Index. It reflects market expectations of near-term uncertainty. Each national EPU index is estimated as newspaper articles information in the explored nation, which contains three terms relating to economics (E), politics (P), and uncertainty (U). So, each value of the EPU's national index monthly is proportional to the number of national newspaper articles discussing economic policy uncertainty during the current month. We reveal the results from the moving correlation in Figure 2.We observe that VSTOXX and EPU move relatively closely between 2000-2006 with similar directions. Our results prove that the correlation between the explored varies between $49 \%$ to $72 \%$ during the pre-crisis period (2000-2006). 
We observe that VSTOXX and EPU move relatively closely between 2000-2006 with similar directions. Our results prove that the correlation varies between $49 \%$ to $72 \%$ during the pre-crisis period (2000-2006). In 2007 and 2008 we observe a relative decrease in the correlation coefficients.
This reduction is a short-term process. For the period 2009-2017, the correlation is pertinently high. In 2017 there was a significant disconnection between the explored variables with correlation down to $38 \%$

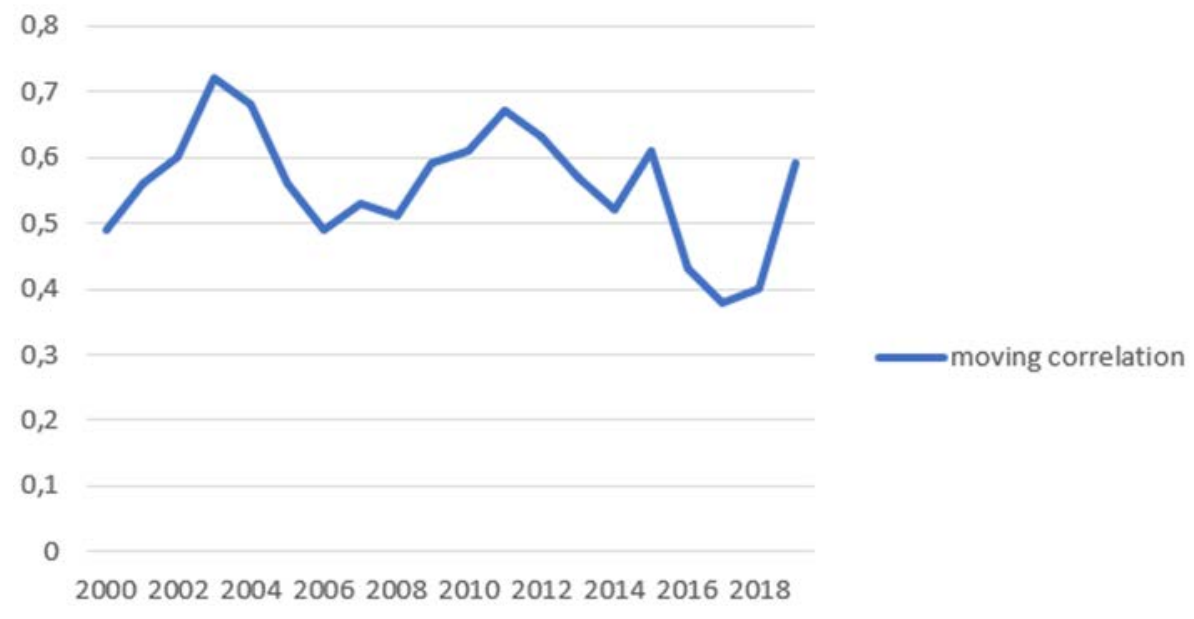

Figure 2:Moving correlation between VSTOXX and EPU

This may be explained by the "volatility paradox". Prolonged low market volatility can introduce risks to financial stability through at least three channels. First, investors could respond by directly taking on Volatility decreases when markets rise and increases when markets fall. The dependence is in the following direction from capital market movements to volatility, not the other way around. Low volatility usually reflects an expanded bullish market. In other words, volatility is a lagging indicator. We observe different correlation levels during the following periods with high uncertainty - the financial crisis and the COVID-19 pandemic. Nowadays, the uncertainty is highly correlated with the risk appetite of the investors and market participants. The aforementioned is proved by the high correlation levels in 2019 and the first months of 2020 . It ranges at about $60 \%$. Because VSTOXX estimates the implied volatility of options one month before their expiration and EPU estimates the long-term risks, their correlation may deviate in the short-run. According to [7] the low financial volatility supposes that markets are overly optimistic about the short-term outlook and are underestimating the risks, including economic policy-related ones. The increasing correlation and the significant effect of the pandemic on stock markets may be accepted as an early and reliable measure of the expected risks. Nowadays is time to propose and construct legal mechanisms that are flexible enough to find the required balance between the national and European interests [8].

\section{Conclusion}

Measuring the economic impact of the COVID-19 pandemic is essential for policymakers, investors, and marketmakers. It is a great challenge for them because the crisis has spread with high speed and with negative consequences on the global economy. In this paper, we explore the economic impact of COVID-19 on the economic activity of Bulgaria and its relation to the economic uncertainty in the European financial markets. We reveal that COVID 19 is a supply-demand shock that 
leads to a reduction of the productive capacity of the Bulgarian economy.

The uncertainty of this pandemic causes shrinks of the demand in the private sector and an increase in the households' savings and reduction in their expenditures. The Bulgarian GDP is forecast to contract by almost $7.6 \%$ According to the results, much stronger than during the Global Financial Crisis in 2009. Because of the high uncertainty of the economic impact of the pandemic it is really difficult for policymakers to formulate a list of effective actions in macroeconomic policy response. We prove high levels of correlation between the EPU and VSTOXX. These results confirm that the impact of the COVID-19 pandemic is not permanently concentrated and it provokes stock market shocks and high volatility. The uncertainty on the future impacts investors' behavior, their risk appetite, and the decline in global growth.

\section{References}

[1] Baker, S., Bloom, N., Davis, St. and Terry, St. COVID-Induced Economic Uncertainty. NBER Working paper Series 26983, 2020.

[2] Demertzis, M., Tagliapietra, S. and Wolff, G. An effective economic response to the coronavirus in Europe, Policy Contribution 06/2020, Bruegel,2020.

[3] Kohlscheen, E., Mojon, B. and Rees, D., The macroeconomic spillover effects of the pandemic on the global economy. BIS Bulletin No.4, 2020.

[4] European Comission, European Economic Forecast, Institutional Paper 125, 2020.

[5] Masten, A., Breznikar, M., Caka, P., Lindic, M., Petricek, M., Ploj, G., Radovan, J., Sosic, N. and Zomo, R. Assessing the impact of the COVID-19 Outbreak of the Slovenian Economic Outlook. Bank of Slovenia, 2020.

[6] McKibbin, W. and Fernando, R. The Global Macroeconomic Impacts of COVID-19: Seven Scenarios,CAMA Working Paper 19/2020, 2020

[7] Economic Baker, S., Bloom, N., Davis, St. and Terry, St. COVID-Induced Economic Uncertainty.NBER Working paper Series 26983, 2020.

[8] Marin, N. Nationalism versus Solidarity in Case of EU Law and Security. International Conference KNOWLEDGE-BASED ORGANIZATION Vol. XXIV,No 2, 2018. 